IP $\rightleftharpoons$ B

\title{
Estrutura e composição da regeneração natural em um fragmento de Floresta Ombrófila Mista secundária
}

\author{
Joelmir Augustinho Mazon ${ }^{1 *}$ (D), Richeliel Albert Rodrigues Silva ${ }^{1}$ (i), Luciano Farinha Watzlawick ${ }^{1}$ (i) \\ ${ }^{1}$ Universidade Estadual do Centro-Oeste, Laboratório de Ciências Florestais e Forrageiras, Rua Simeão Camargo Varela de Sá, n 3 , CEP 85040-080, Guarapuava, \\ PR, Brasil
}

\begin{abstract}
"Autor correspondente:
joelmir23@hotmail.com
\end{abstract}

Termos para indexação:

Índice de regeneração natural total

Floresta com Araucária

Estrato arbóreo adulto

Index terms:

Total Natural Regeneration Index

Araucaria forests

Adult arboreal stratum

Histórico do artigo:

Recebido em 14/08/2018

Aprovado em 10/04/2019

Publicado em 31/12/2019

Trabalho apresentado no V Seminário de Atualização Florestal, 24 e 28 de setembro de 2018, Irati, PR.
Resumo - Estudos sobre regeneração natural e sua relação com a vegetação adulta são importantes para auxiliar no entendimento da dinâmica e sucessão de florestas secundárias. Para tanto, objetivou-se, neste estudo, realizar a caracterização florísticoestrutural e ecológica da comunidade regenerativa (DAP $<5 \mathrm{~cm}$ ) e sua similaridade com a adulta (DAP $\geq 5 \mathrm{~cm}$ ) em um fragmento de Floresta com Araucária secundária. A regeneração foi amostrada em 24 parcelas em três classes de altura, sendo calculada a regeneração natural total (RNT). Foram amostrados 433 indivíduos, pertencentes a 66 espécies e 29 famílias botânicas, com destaque para Myrtaceae. A similaridade florística entre a regeneração e o estrato adulto foi alta $(68,3 \%)$. A regeneração e o estrato adulto apresentaram alta diversidade e equitatividade e baixa dominância. Allophylus edulis (9,5\%), Mollinedia clavigera (8,5\%) e Myrciaria tenella (8,3\%) foram as espécies de maior RNT. Porém, são típicas de sub-bosque e não apresentam importância no estrato adulto. As demais espécies destacadas na regeneração, entre elas espécies-chave como Ocotea porosa, devem seguir na estrutura futura da floresta. A maioria das espécies da regeneração são zoocóricas e heliófilas, porém a proporção de espécie de estágio tardio é maior na classe de maior tamanho, indicando que a floresta está em plena sucessão e avançando para seu clímax.

\section{Structure and composition of natural regeneration in a fragment of a secondary Araucaria Forest}

\begin{abstract}
Research on natural regeneration and its relationship with adult vegetation are important to subsidize the understanding of succession of secondary forests. The aims of this study was to characterize the ecological and floristic structure of the regenerative community $(\mathrm{DHB}<5 \mathrm{~cm}$ ) and its similarity to adult strata (DHB $\geq 5$ $\mathrm{cm}$ ), in a forest secondary Araucaria Forest fragment. Regeneration was sampled in 24 plots in three height classes and total natural regeneration (TNR) was calculated. We sampled 433 plants, belonging to 66 species and 29 botanical families, with emphasis on Myrtaceae. The floristic similarity between regeneration and the adult strata was high $(68.3 \%)$. Regeneration and adult strata presented high diversity and equitability and low dominance. Allophylus edulis (9.5\%), Mollinedia clavigera (8.5\%) and Myrciaria tenella $(8.3 \%)$ were the species which showed the highest TNR. They are typical of understory and they are not important in the adult strata. However, other important species in the regeneration, among them key species such as Ocotea porosa (Brazilianwalnut) should continue in the future structure of the forest. Most regeneration species are zoocoric and heliophilous, but the proportion of late stage species is higher in the larger size class, indicating that the forest is in full succession and evolving to its climax.
\end{abstract}




\section{Introdução}

A regeneração em florestas se desenvolve a partir de processos de sucessão secundária em uma comunidade vegetal de determinada área após perturbações naturais ou não em sua estrutura, como desbastes, abertura de clareiras ou pela supressão da vegetação original. Este fenômeno evolui por uma progressão de estágios de enriquecimento gradual das espécies, resultando no aumento da complexidade estrutural e funcional da floresta, onde os táxons de crescimento rápido, com alta tolerância à radiação solar e abundante dispersão de sementes, vão sendo substituídos por espécies umbrófilas, que demandam maior investimento energético nas sementes, crescimento mais lento e consequente longevidade (Chazdon, 2012).

Segundo Lugo (2009), atualmente a maioria dos ecossistemas e suas comunidades florestais encontramse em estágio secundário de sucessão, resultante não só de eventos naturais estocásticos, mas principalmente relacionados ao uso do solo que, em diferentes níveis, causam alguma perturbação e as desestruturam. Assim, a conversão das comunidades florestais primárias em secundárias tem despertado o interesse da comunidade científica e da sociedade em geral, pelo importante papel dos serviços ecossistêmicos e de bens consumíveis que estas apresentam, apesar de que no Brasil a visão é ainda muito preservacionista (Piazza et al., 2017).

Por apresentar padrões de desenvolvimento, o estudo da regeneração, em especial em florestas secundárias, é elementar para a identificação, determinação e prognóstico dos processos fundamentais envolvidos na progressão das comunidades vegetais e para modelagem de suas seres em decorrência de perturbações ambientais ou climáticas.

Dentre os ecossistemas florestais brasileiros que mais sofrem com a exploração e conversão de áreas florestadas para o uso na agricultura, pecuária e urbanismo, destacase a Floresta Ombrófila Mista (FOM), que tem seu clímax climático no Planalto Meridional no Sul do Brasil (Martins \& Cavararo, 2012). De acordo com Medeiros et al. (2005), a FOM teve ápice de degradação entre as décadas de 1930 e 1980, onde a madeira da Araucaria angustifolia (Bertol.) Kuntze, espécie ícone desta sinúsia, era um dos principais produtos de uso interno e exportação do país, levando à substancial retirada de cobertura vegetal no Sul do Brasil, em especial no Paraná, onde as áreas de floresta natural encontram-se em grande parte em um mosaico de fragmentos em estágio secundário de sucessão.

Em razão da grande fragmentação em que Floresta Ombrófila Mista se encontra e das consequências geradas por restrições de fluxos gênicos, com eventual perda de biodiversidade, Ribeiro et al. (2013) advertem sobre a urgência da aquisição de informações sobre a composição, estrutura, riqueza e dinâmica sucessional, para a ampliação dos conhecimentos sobre as variações florísticas e estruturais nos trechos de sua ocorrência natural. Porém, é notório que a maioria dos trabalhos referentes à esta região fitogeográfica abordam a estrutura arbórea, havendo uma lacuna para estudos de regeneração florestal para a Floresta Ombrófila Mista.

O estudo da regeneração natural possibilita a melhor compreensão da autoecologia e sinecologia das espécies ao longo do processo de sucessão em que estão inseridas e podem indicar possíveis consequências de impactos antrópicos realizados em florestas, como alterações nos padrões de riqueza e consequentes efeitos na equitatividade e dominância na comunidade vegetal. Com o entendimento destas informações, é possível avaliar a capacidade e o potencial regenerativo de algumas espécies ou guildas que são capazes de se estabelecerem no sub-bosque de determinadas florestas, sob diferentes condições ambientais e níveis de distúrbio (Aguiar et al., 2017). De acordo com Aide et al. (2000), a regeneração florestal é justamente uma ferramenta de baixo custo para projetos de recuperação e restauração da biodiversidade, pois baseia-se nestes pressupostos e princípios naturais de sucessão ecológica.

Em geral, os trabalhos de maior destaque sobre regeneração natural em Floresta Ombrófila Mista no Sul do Brasil são realizados no Rio Grande do Sul e em Santa Catarina. No caso do Paraná, mesmo sendo o estado de maior cobertura original da fitofisionomia e que apresenta elevada fragmentação de suas florestas, os levantamentos da regeneração natural são exíguos (Barddal et al., 2004; Cordeiro \& Rodrigues, 2007; Lima et al., 2013 e Albuquerque, 2016), preconizando a realização de mais estudos neste sentindo para melhor conhecimento dos processos de sucessão natural desta fitofisionomia no Estado.

Em face à grande fragmentação e conversão em florestas secundárias das áreas naturais de Floresta com Araucária e ao escasso número de estudos relativos à estrutura, composição e sucessão da regeneração natural desta floresta, em especial no estado do Paraná, 
este estudo teve como objetivo realizar a caracterização florístico-estrutural da regeneração em diferentes classes de tamanho e entre o estrato adulto, fortalecendo o conhecimento da sucessão florestal de fragmentos de Floresta Ombrófila Mista secundária e arrazoando sobre quais são as espécies com maior potencial de regeneração de seguirem na estrutura futura da floresta.

\section{Metodologia}

O estudo foi conduzido em um fragmento florestal no Sítio Edelweiss, localizado no município de Turvo, no centro-sul do estado do Paraná, entre as coordenadas geográficas E $446175 \mathrm{~m}$ e S $7228508 \mathrm{~m}$, Fuso 22J, a uma altitude média de $1.080 \mathrm{~m}$ s.n.m. O clima da região é do tipo Subtropical Úmido Mesotérmico $(\mathrm{Cfb})$, conforme a classificação de Köppen-Geiger, com verões amenos, pluviosidade alta e bem distribuída ao longo do ano, podendo atingir a média anual de $2.000 \mathrm{~mm}$, sem período seco marcante e com ocorrência de geadas severas (Alvares et al., 2013). Os solos deste local se apresentam em relevo com variação entre plano e suave ondulado e são classificados como Latossolo Bruno Distrófico, pelo Sistema Brasileiro de Classificação de Solos (Santos et al., 2013).

Segundo Martins \& Cavararo (2012), devido ao seu patamar altimétrico, a área de estudo localiza-se na faixa de ocorrência natural de Floresta Ombrófila Mista Alto-Montana, caracterizada pela menor diversidade florística, influenciada pelas condições ambientais do maior gradiente altitudinal, porém, com presença ainda marcante da conífera Araucaria angustifolia (Bertol.) Kuntze e das folhosas Myrtaceae, Lauraceae, Sapindaceae, Meliaceae, Winteraceae, dentre outras famílias de plantas lenhosas.

O fragmento florestal estudado possui um histórico de conversão de floresta natural para Sistema Faxinal, realizada na década de 1970 , quando ocorreu o raleamento do sub-bosque e prática de circulação de animais domésticos, como aves, suínos, equinos e bovinos. Na década de 1980, houve isolamento e conversão do local em área de piquetes de forragem para bovinos e caprinos. No decorrer da década de 1990 o local foi novamente isolado e averbado como Reserva Legal da propriedade, onde permitiu-se a regeneração da florestal resultando atualmente em um fragmento em estágio de sucessão florestal intermediário.
Em 2013 o fragmento de mata da Reserva Legal teve sua área demarcada para fins de estudos de sua vegetação lenhosa pelo Laboratório de Ciências Florestais e Forrageiras da Universidade Estadual do Centro-Oeste (Mazon, 2014), resultando na instalação de uma unidade amostral de 1,8 ha, subdividida em 42 subunidades de $400 \mathrm{~m}^{2}$ (20 m x $20 \mathrm{~m}$ ) e seis subunidades de borda de $200 \mathrm{~m}^{2}$ (10 m x $20 \mathrm{~m}$ ) (Figura 1a). Para a amostragem de dados da regeneração natural foram selecionadas sistematicamente 24 destas subunidades. Foi instalado um piquete no centro do primeiro quadrante de cada subunidade, em plano cartesiano-ortogonal a $7 \mathrm{~m}$ na diagonal do canto superior esquerdo da parcela (Figura 1b).

A regeneração natural arbustivo-arbórea foi amostrada com a utilização de três categorias de área de parcelas circulares (Figura 1c), tendo como ponto central cada um dos 24 piquetes selecionados, conforme os seguintes critérios adotados para classes de altura $(\mathrm{H})$ : Classe 1 (C1): Todos os indivíduos lenhosos em regeneração com $20 \mathrm{~cm} \leq \mathrm{H} \leq 50 \mathrm{~cm}$ e diâmetro à altura do colo (DAC) $<5 \mathrm{~cm}$, dentro de uma parcela circular de $1 \mathrm{~m}^{2}$ (Raio $=$ $0,55 \mathrm{~cm})$; Classe $2(\mathrm{C} 2)$ : Todos os indivíduos lenhosos com $50 \mathrm{~cm} 51 \mathrm{~cm} \leq \mathrm{H} \leq 1,30 \mathrm{~m}$ e DAC $<5 \mathrm{~cm}$, dentro de uma parcela circular de $4 \mathrm{~m}^{2}$ (Raio $=1,12 \mathrm{~m}$ ); Classe 3 (C3): Todos os indivíduos lenhosos com $\mathrm{H}>1,3 \mathrm{~m}$, e diâmetro a $1,30 \mathrm{~m}$ do solo (DAP) $<5 \mathrm{~cm}$, dentro da parcela circular de $9 \mathrm{~m}^{2}($ Raio $=1,7 \mathrm{~m})$.

A amostragem em diferentes classes de altura teve como intuito cobrir o maior espectro ontogênico possível na estrutura florístico-estrutural da comunidade em regeneração (Aguiar et al., 2017), pois estas espécies podem apresentar tamanhos diferentes ao longo do processo de sucessão, decorrentes de sua autoecologia nos gradientes ecológicos e microambientais que possam enfrentar na floresta.

As espécies amostradas foram identificadas e classificadas conforme os critérios da APG IV (Chase et al., 2016). A suficiência amostral foi testada com o uso da curva de rarefação pelo Método Mao Tau, comparado também com o estimador Bootstrap, baseado na incidência de espécies. Estes métodos estimam a verdadeira diversidade de um sistema e o esforço amostral necessário para obter uma aproximação admissível da riqueza de espécies. O uso destes estimadores é apropriado, quando a diversidade real de uma comunidade é desconhecida e quando as populações amostradas são compostas por várias subpopulações não identificadas (Gotelli \& Colwell, 2011). 


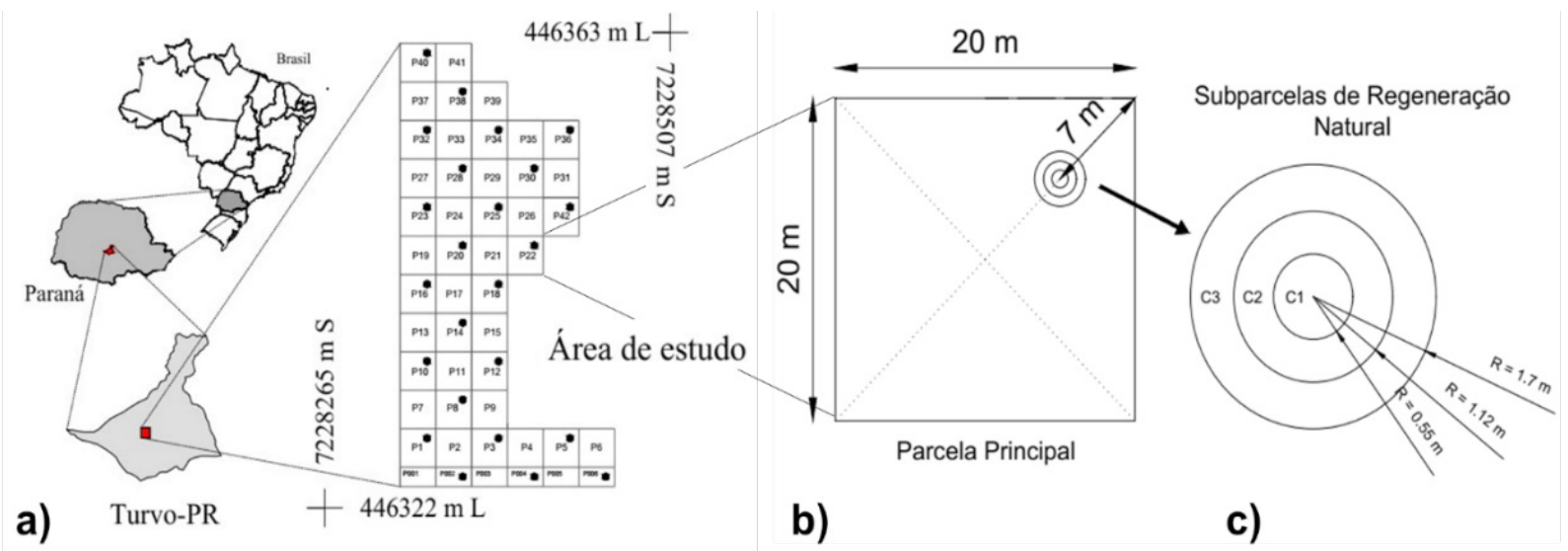

Figura 1. a) Localização da área de estudo, unidade amostral e os pontos onde foram amostrados os dados do levantamento da regeneração natural em uma Floresta Ombrófila Mista secundária em Turvo, PR. b) Localização das parcelas circulares; c) Dimensões das parcelas circulares para a regeneração natural em cada classe de tamanho.

Figure 1. a) Location of the survey area, sampling unit and natural regeneration survey plots in a secondary Araucaria Forest in Turvo, Paraná State, Brazil. b) Location of the circular plots; c) Dimensions of circular plots for natural regeneration in each height size class.

Para avaliar a estrutura fitossociológica da regeneração foi calculado o potencial da regeneração natural total (RNT), para diferentes classes de altura mensuradas em parcelas com diferentes tamanhos de área, com o propósito de avaliar a regeneração total da espécie por meio da soma das classes de tamanho consideradas, derivado da frequência e densidade (Volpato, 1994). As equações 1 e 2 foram utilizadas para o cálculo da densidade da regeneração natural absoluta e relativa, respectivamente.

$$
\begin{gathered}
D A R_{\mathrm{ij}}=\frac{n_{\overline{i j}}}{A} \\
D R R_{i \mathrm{j}}=\frac{D A R_{\mathrm{ij}}}{\sum_{J=1}^{3} D A R_{\overline{i j}}} \times 100
\end{gathered}
$$

Onde: $\mathrm{DAR}_{\mathrm{ij}}=$ densidade absoluta da regeneração da i-ésima espécie na j-ésima classe de tamanho; $\mathrm{DRR}_{\mathrm{ij}}$ $=$ densidade relativa da regeneração da i-ésima espécie na $\mathrm{j}$-ésima classe de tamanho; $\mathrm{A}=$ área total amostrada por parcela por classe de tamanho (ha); $\mathrm{n}_{\mathrm{ij}}=$ número de indivíduos da i-ésima espécie na j-ésima classe de tamanho.

As equações 3 e 4 foram utilizadas para o cálculo da frequência da regeneração natural absoluta e relativa, respectivamente.

$$
\begin{gathered}
F A R_{\mathrm{ij}}=\frac{u_{\mathrm{ij}}}{U_{T}} \times 100 \\
F R R_{\mathrm{ij}}=\frac{F A R_{\mathrm{ij}}}{\sum F A R_{\mathrm{ij}}} \times 100
\end{gathered}
$$

Onde: $\mathrm{FAR}_{\mathrm{ij}}=$ frequência absoluta da regeneração da i-ésima espécie na j-ésima classe de tamanho; $\mathrm{FRR}_{\mathrm{ij}}=$ frequência relativa da regeneração da i-ésima espécie na j-ésima classe de tamanho; $\mathrm{u}_{\mathrm{ij}}=$ número de parcelas de ocorrência da i-ésima espécie por classe de tamanho; $\mathrm{U}_{\mathrm{t}}=$ total de parcelas amostradas.

Finalmente, com base nesses parâmetros de densidade relativa (DRR) e frequência relativa (FRR), estimou-se a regeneração natural por classe de altura (RNC) (equação 5) e o cálculo da estimativa da regeneração da população amostrada por espécie, utilizando-se a soma dos índices de regeneração natural por classe de altura, obtendo-se o índice de regeneração total (RNT) (equação 6).

A comparação florística, estrutural e ecológica entre a comunidade em regeneração com a comunidade do estrato adulto também foi realizada. Para tanto, foram utilizados os parâmetros fitossociológicos de densidade relativa (DR\%), dominância relativa (DoR\%) e valor de importância (VI\%), oriundos do inventário realizado em todas as parcelas principais do local (Figura 1a), 
incluindo todos indivíduos lenhosos com DAP $\geq 5 \mathrm{~cm}$ (Mazon, 2014).

$$
\begin{aligned}
R N C_{\mathrm{ij}} & =\frac{D R R_{\mathrm{ij}}+F R R_{\mathrm{ij}}}{2} \\
R N T_{\mathrm{i}} & =\frac{\sum_{\mathrm{j}=1}^{\mathrm{I}}\left(R N C_{\mathrm{ij}}\right)}{3}
\end{aligned}
$$

Onde: $\mathrm{RNC}_{\mathrm{ij}}=$ regeneração natural da i-ésima espécie na j-ésima classe de tamanho e $\mathrm{RNT}_{\mathrm{i}}=$ regeneração natural total da i-ésima espécie.

O grau de similaridade florística entre a regeneração natural nas diferentes classes de tamanho (RNC 1, 2, 3) a RNT e o estrato adulto foi obtido por meio do índice de similaridade de Sørensen (ISS), com a utilização de matrizes de presença e ausência de indivíduos de cada espécie.

Para a estimativa da diversidade, tanto da comunidade regenerativa quanto do estrato adulto, foi calculado o índice de Shannon (H'), assim como a equitatividade da relação taxa $\mathrm{x}$ indivíduos pelo índice de equitatividade de Pielou (J') e a detecção de possível dominância de uma ou mais espécies, por meio do índice de dominância Simpson (D) (Freitas \& Magalhães, 2012).

As espécies encontradas na regeneração e no estrato adulto foram caracterizadas por sua síndrome de dispersão de diásporos, conforme os princípios de Van Der Pijl (1982), em: zoocoria (ZO), anemocoria (AN) e autocoria (AU).
Por fim, foi realizada a classificação sucessional em grupos ecológicos das espécies encontradas na regeneração e que também estão presentes no estrato adulto. Devido ao elevado nível de subjetividade e abstração das informações encontradas para este tipo de classificação, foi interpolada uma caracterização sucessional mais simplificada. Para tanto, tomou-se como base bibliográfica os seguintes trabalhos realizados em Floresta Ombrófila Mista: Grings \& Brack (2009), Klauberg et al. (2010), Zama et al. (2012), Ferreira et al. (2013), Silva et al. (2013), Ebling et al. (2014) e Seubert et al. (2017), onde as espécies consideradas como pioneiras e secundárias iniciais foram incluídas no grupo de plantas de estágios iniciais (EI) e espécies secundárias tardias e clímax como estágios tardios (ET).

\section{Resultados}

Foram amostrados 433 indivíduos arbustivo-arbóreos (49.383 ind ha $^{-1}$ ) na regeneração natural total (RNT) nas 24 parcelas circulares. Observou-se um decréscimo da densidade de indivíduos com o aumento da classe de tamanho ( $\mathrm{RNC} 1,2,3$ ). Por outro lado, a riqueza específica e a diversidade florística foram superiores nas classes de tamanho maiores e em relação ao estrato adulto. As espécies estão equitativamente bem distribuídas entre os indivíduos e não apresentam tendência à dominância por uma ou mais espécies, tanto na regeneração como no estrato adulto (Tabela 1).

Tabela 1. Valores de densidade e índices de diversidade da comunidade arbustivo-arbórea em regeneração por classe de altura (RNC), regeneração natural total (RNT) e estrato arbóreo adulto de um fragmento de Floresta Ombrófila Mista secundária em Turvo, PR.

Table 1. Density values and diversity indexes of the woody regeneration community by height class (RNC), total natural

\begin{tabular}{|c|c|c|c|c|c|c|c|}
\hline Classe/Estrato & $\mathbf{N}$ & $\begin{array}{c}\begin{array}{c}\text { Área } \\
\text { amostrada } \\
\text { (ha) }\end{array}\end{array}$ & $\begin{array}{c}\text { Densidade } \\
\text { absoluta (ind. } \\
\text { ha }^{-1} \text { ) }\end{array}$ & $\begin{array}{c}\text { Riqueza } \\
\text { específica } \\
\text { (S) }\end{array}$ & $\begin{array}{c}\text { Diversidade de } \\
\text { Shannon (H') }\end{array}$ & $\begin{array}{l}\text { Equitatividade de } \\
\text { Pielou (J') }\end{array}$ & $\begin{array}{c}\text { Dominância de } \\
\text { Simpson (D) }\end{array}$ \\
\hline $\mathrm{RNC1}$ & 55 & 0,002 & 22.917 & 20 & 2,77 & 0,92 & 0,08 \\
\hline $\mathrm{RNC2}$ & 155 & 0,010 & 16.146 & 35 & 2,85 & 0,80 & 0,08 \\
\hline RNC3 & 223 & 0,022 & 10.324 & 46 & 3,37 & 0,88 & 0,05 \\
\hline RNT & 433 & 0,034 & 49.387 & 54 & 3,32 & 0,83 & 0,05 \\
\hline Adulto & 2.031 & 1,800 & 1.128 & 66 & 3,25 & 0,78 & 0,06 \\
\hline
\end{tabular}
regeneration (RNT) and arboreal stratum of a secondary Araucaria Forest fragment in Turvo, Paraná State, Brazil.

Onde: $\mathrm{RNC} 1=$ todos os indivíduos lenhosos em regeneração com $20 \mathrm{~cm} \leq$ altura $(\mathrm{H}) \leq 50 \mathrm{~cm}$ e diâmetro à altura do colo $(\mathrm{DAC})<5 \mathrm{~cm}$; RNC2 $=$ Todos os indivíduos lenhosos com $51 \leq \mathrm{H} \leq 1,30 \mathrm{~m}$ e DAC $<5 \mathrm{~cm}$; RNC3 = todos os indivíduos lenhosos com $\mathrm{H}>1,3 \mathrm{~m}$, e diâmetro a 1,30 m do solo (DAP) $<5 \mathrm{~cm}$. 
A composição florística para a (RNT) é representada por 54 espécies pertencentes a 40 gêneros e 29 famílias botânicas (Tabela 2). As famílias botânicas de maior representatividade na RNT foram Myrtaceae (12 espécies), Lauraceae (4), Salicaceae, Euphorbiaceae e Sapindaceae (3 espécies cada), muito semelhante ao estrato adulto, onde as famílias com maior destaque foram Myrtaceae (10), Lauraceae (9), Salicaceae (5), Euphorbiaceae e Asteraceae (4 espécies cada) e Sapindaceae (3).

O estrato adulto é composto por 66 espécies, das quais 24 são exclusivas desse estrato, 44 são compartilhadas com o estrato em regeneração, e 13 são exclusivas da comunidade em regeneração.

Tabela 2. Composição florística, estrutura, síndromes de dispersão e classificação ecológica de espécies da regeneração natural e densidade e frequência dos representantes arbustivo-arbóreos do estrato adulto de um fragmento de Floresta Ombrófila Mista secundária em Turvo, PR.

Table 2. Floristic composition, structure, dispersion syndromes and ecological classification of natural regeneration species, and density and frequency of arbustive-trees species representative of the adult stratum of a secondary Araucaria Forest fragment in Turvo, Paraná State, Brazil.

\begin{tabular}{|c|c|c|c|c|c|c|c|c|c|c|c|}
\hline \multirow[b]{2}{*}{ Família/Nome científico } & \multicolumn{7}{|c|}{ Estrato de regeneração } & \multicolumn{4}{|c|}{ Estrato adulto } \\
\hline & $\mathbf{N}$ & $\begin{array}{c}\text { RNC1 } \\
(\%)\end{array}$ & $\begin{array}{c}\text { RNC2 } \\
(\%)\end{array}$ & $\begin{array}{c}\text { RNC3 } \\
(\%)\end{array}$ & $\begin{array}{c}\text { RNT } \\
(\%)\end{array}$ & SD & CS & $\begin{array}{l}\text { DR } \\
(\%)\end{array}$ & $\begin{array}{l}\text { DoR } \\
(\%)\end{array}$ & $\begin{array}{l}\text { FR } \\
(\%)\end{array}$ & $\begin{array}{r}\text { VI } \\
(\%)\end{array}$ \\
\hline \multicolumn{12}{|l|}{ ANNONACEAE } \\
\hline Annona sylvatica A. St.-Hil. & 2 & 1,0 & 0,2 & 0,0 & 1,2 & $\mathrm{Zc}$ & EI & 0,0 & 0,0 & 0,1 & 0,1 \\
\hline \multicolumn{12}{|l|}{ AQUIFOLIACEAE } \\
\hline Ilex paraguariensis A. St.-Hil. & 6 & 0,0 & 0,2 & 1,0 & 1,2 & $\mathrm{Zc}$ & ET & 9,1 & 1,8 & 5,4 & 5,4 \\
\hline Ilex theezans Mart. ex Reissek & 1 & 0,0 & 0,0 & 0,3 & 0,3 & $\mathrm{Zc}$ & EI & 1,2 & 0,6 & 2,9 & 1,6 \\
\hline \multicolumn{12}{|l|}{ ARAUCARIACEAE } \\
\hline Araucaria angustifolia (Bertol.) Kuntze & 2 & 0,0 & 0,0 & 0,5 & 0,5 & $\mathrm{Zc}$ & EI & 8,7 & 5,8 & 4,9 & 6,5 \\
\hline \multicolumn{12}{|l|}{ ARECACEAE } \\
\hline Syagrus romanzoffiana (Cham.) Glassman & 2 & 0,0 & 0,1 & 0,3 & 0,4 & $\mathrm{Zc}$ & EI & 0,6 & 0,6 & 1,2 & 0,8 \\
\hline \multicolumn{12}{|l|}{ ASTERACEAE } \\
\hline Vernonanthura discolor (Spreng.) H. Rob. & 7 & 0,0 & 0,1 & 1,5 & 1,6 & An & EI & 8,6 & 5,7 & 4,8 & 6,4 \\
\hline \multicolumn{12}{|l|}{ BIGNONIACEAE } \\
\hline Jacaranda micrantha Cham. & 1 & 0,0 & 0,0 & 0,3 & 0,3 & An & EI & 0,6 & 0,4 & 1,2 & 0,7 \\
\hline \multicolumn{12}{|l|}{ BORAGINACEAE } \\
\hline Cordia ecalyculata Vell. & 23 & 1,2 & 1,9 & 1,4 & 4,5 & $\mathrm{Zc}$ & EI & 1,5 & 0,9 & 1,9 & 1,5 \\
\hline \multicolumn{12}{|l|}{ CANNABACEAE } \\
\hline Celtis iguanaea (Jacq.) Sarg. & 1 & 0,0 & 0,0 & 0,3 & 0,3 & $\mathrm{Zc}$ & EI & - & - & - & - \\
\hline \multicolumn{12}{|l|}{ CLETHRACEAE } \\
\hline Clethra scabra Pers. & 5 & 0,0 & 0,0 & 0,9 & 0,9 & An & EI & 7,5 & 5,3 & 4,6 & 5,8 \\
\hline \multicolumn{12}{|l|}{ CUNONIACEAE } \\
\hline Lamanonia ternata Vell. & 5 & 0,0 & 0,0 & 1,1 & 1,1 & An & EI & 2,4 & 3,6 & 3,1 & 3,1 \\
\hline \multicolumn{12}{|l|}{ EUPHORBIACEAE } \\
\hline Gymnanthes klotzschiana Müll. Arg. & 19 & 1,2 & 1,5 & 1,0 & 3,7 & $\mathrm{Au}$ & EI & 0,1 & 0,1 & 0,1 & 0,1 \\
\hline Sapium glandulosum (L.) Morong & 1 & 0,0 & 0,0 & 0,3 & 0,3 & $\mathrm{Au}$ & EI & 0,5 & 0,7 & 1,2 & 0,8 \\
\hline Sebastiania brasiliensis Spreng. & 1 & 0,0 & 0,0 & 0,3 & 0,3 & $\mathrm{Au}$ & EI & 0,0 & 0,0 & 0,1 & 0,1 \\
\hline \multicolumn{12}{|l|}{ FABACEAE } \\
\hline Lonchocarpus nitidus (Vogel) Benth. & 1 & 0,0 & 0,0 & 0,3 & 0,3 & An & EI & - & - & - & - \\
\hline
\end{tabular}


Tabela 2. Continua...

Table 2. Continuation...

\begin{tabular}{|c|c|c|c|c|c|c|c|c|c|c|c|}
\hline \multirow[b]{2}{*}{ Família/Nome científico } & \multicolumn{7}{|c|}{ Estrato de regeneração } & \multicolumn{4}{|c|}{ Estrato adulto } \\
\hline & $\mathbf{N}$ & $\begin{array}{c}\text { RNC1 } \\
(\%)\end{array}$ & $\begin{array}{l}\text { RNC2 } \\
(\%)\end{array}$ & $\begin{array}{c}\text { RNC3 } \\
(\%)\end{array}$ & $\begin{array}{c}\text { RNT } \\
(\%)\end{array}$ & SD & CS & $\begin{array}{l}\text { DR } \\
(\%)\end{array}$ & $\begin{array}{l}\text { DoR } \\
(\%)\end{array}$ & $\begin{array}{l}\text { FR } \\
(\%)\end{array}$ & $\begin{array}{r}\text { VI } \\
(\%)\end{array}$ \\
\hline \multicolumn{12}{|l|}{ LAURACEAE } \\
\hline $\begin{array}{l}\text { Cinnamomum sellowianum (Nees \& C. Martius ex } \\
\text { Nees) Kosterm. }\end{array}$ & 12 & 2,0 & 0,9 & 1,0 & 3,9 & $\mathrm{Zc}$ & ET & 1,4 & 1,3 & 1,7 & 1,5 \\
\hline Nectandra megapotamica (Spreng.) Mez & 2 & 0,0 & 0,0 & 0,5 & 0,5 & $\mathrm{Zc}$ & ET & 0,0 & 0,0 & 0,1 & 0,1 \\
\hline Ocotea diospyrifolia (Meisn.) Mez & 1 & 0,0 & 0,0 & 0,3 & 0,3 & $\mathrm{Zc}$ & ET & 0,1 & 0,0 & 0,3 & 0,2 \\
\hline Ocotea porosa (Nees) Barroso & 11 & 1,0 & 0,8 & 0,8 & 2,6 & $\mathrm{Zc}$ & ET & 2,0 & 22,5 & 3,5 & 9,3 \\
\hline \multicolumn{12}{|l|}{ MALVACEAE } \\
\hline Luehea divaricata Mart. \& Zucc. & 2 & 0,0 & 0,1 & 0,3 & 0,4 & An & ET & - & - & - & - \\
\hline \multicolumn{12}{|l|}{ MELASTOMATACEAE } \\
\hline Miconia cinerascens Miq. & 3 & 1,0 & 0,3 & 0,0 & 1,3 & $\mathrm{Zc}$ & EI & - & - & - & - \\
\hline Miconia sellowiana Naudin & 3 & 0,0 & 0,3 & 0,0 & 0,3 & $\mathrm{Zc}$ & EI & 0,1 & 0,0 & 0,3 & 0,2 \\
\hline \multicolumn{12}{|l|}{ MELIACEAE } \\
\hline Cedrela fissilis Vell. & 8 & 0,6 & 0,4 & 1,1 & 2,1 & An & ET & 1,6 & 2,0 & 2,6 & 2,0 \\
\hline \multicolumn{12}{|l|}{ MONIMIACEAE } \\
\hline Mollinedia clavigera Tul. & 56 & 1,2 & 3,9 & 3,4 & 8,5 & $\mathrm{Zc}$ & ET & - & - & - & - \\
\hline \multicolumn{12}{|l|}{ MYRTACEAE } \\
\hline Calyptranthes concinna DC. & 4 & 0,0 & 0,0 & 1,0 & 1,0 & $\mathrm{Zc}$ & ET & 0,1 & 0,1 & 0,3 & 0,2 \\
\hline Campomanesia guazumifolia (Cambess.) O. Berg. & 1 & 0,0 & 0,0 & 0,3 & 0,3 & $\mathrm{Zc}$ & ET & 0,1 & 0,0 & 0,3 & 0,2 \\
\hline Campomanesia xanthocarpa O. Berg & 21 & 1,2 & 1,1 & 1,9 & 4,2 & $\mathrm{Zc}$ & ET & 3,5 & 3,0 & 4,1 & 3,6 \\
\hline Eugenia hiemalis Cambess. & 1 & 0,0 & 0,1 & 0,0 & 0,1 & $\mathrm{Zc}$ & EI & 0,2 & 0,1 & 0,3 & 0,2 \\
\hline Eugenia uniflora $\mathrm{L}$. & 3 & 0,0 & 0,1 & 0,3 & 0,4 & $\mathrm{Zc}$ & ET & 0,2 & 0,1 & 0,5 & 0,2 \\
\hline Myrcia guianensis (Aubl.) DC. & 1 & 0,0 & 0,0 & 0,3 & 0,3 & $\mathrm{Zc}$ & EI & - & - & - & - \\
\hline Myrcia hebepetala DC. & 4 & 0,0 & 0,0 & 1,0 & 1,0 & $\mathrm{Zc}$ & ET & - & - & - & - \\
\hline Myrcia sp. & 1 & 0,0 & 0,0 & 0,3 & 0,3 & $\mathrm{Zc}$ & - & - & - & - & - \\
\hline Myrcia spectabilis DC. & 4 & 0,0 & 0,1 & 0,8 & 0,9 & $\mathrm{Zc}$ & ET & - & - & - & - \\
\hline Myrcianthes pungens (O. Berg) D. Legrand & 2 & 0,0 & 0,1 & 0,3 & 0,4 & $\mathrm{Zc}$ & ET & - & - & - & - \\
\hline Myrciaria delicatula (DC.) O. Berg & 2 & 0,0 & 0,2 & 0,0 & 0,2 & $\mathrm{Zc}$ & ET & - & - & - & - \\
\hline Myrciaria tenella (DC.) O. Berg & 36 & 4,2 & 2,0 & 2,2 & 8,3 & $\mathrm{Zc}$ & ET & 0,2 & 0,1 & 0,5 & 0,2 \\
\hline \multicolumn{12}{|l|}{ PRIMULACEAE } \\
\hline Myrsine coriacea (Sw.) R. Br. & 10 & 0,6 & 0,3 & 1,8 & 2,8 & $\mathrm{Zc}$ & EI & 4,3 & 0,8 & 4,2 & 3,1 \\
\hline Myrsine umbellata Mart. & 34 & 1,2 & 0,9 & 3,6 & 5,7 & $\mathrm{Zc}$ & EI & 7,8 & 2,3 & 4,7 & 4,9 \\
\hline \multicolumn{12}{|l|}{ RHAMNACEAE } \\
\hline Hovenia dulcis Thunb. & 1 & 0,6 & 0,2 & 0,0 & 0,8 & $\mathrm{Zc}$ & EI & 0,0 & 0,0 & 0,1 & 0,1 \\
\hline \multicolumn{12}{|l|}{ ROSACEAE } \\
\hline Prunus myrtifolia (L.) Urb. & 15 & 1,8 & 1,3 & 1,1 & 4,2 & $\mathrm{Zc}$ & EI & 3,2 & 7,0 & 3,6 & 4,6 \\
\hline \multicolumn{12}{|l|}{ RUBIACEAE } \\
\hline Coussarea contracta (Walp.) Müll. Arg. & 10 & 0,6 & 1,0 & 0,5 & 2,1 & $\mathrm{Zc}$ & ET & 0,0 & 0,0 & 0,1 & 0,1 \\
\hline Faramea montevidensis (Cham. \& Schltdl.) DC. & 1 & 0,0 & 0,0 & 0,3 & 0,3 & $\mathrm{Zc}$ & ET & - & - & - & - \\
\hline
\end{tabular}


Tabela 2. Continua...

Table 2. Continuation...

\begin{tabular}{|c|c|c|c|c|c|c|c|c|c|c|c|}
\hline \multirow[b]{2}{*}{ Família/Nome científico } & \multicolumn{7}{|c|}{ Estrato de regeneração } & \multicolumn{4}{|c|}{ Estrato adulto } \\
\hline & $\mathbf{N}$ & $\begin{array}{l}\text { RNC1 } \\
(\%)\end{array}$ & $\begin{array}{l}\text { RNC2 } \\
(\%)\end{array}$ & $\begin{array}{c}\text { RNC3 } \\
(\%)\end{array}$ & $\begin{array}{l}\text { RNT } \\
(\%)\end{array}$ & SD & CS & $\begin{array}{l}\text { DR } \\
(\%)\end{array}$ & $\begin{array}{l}\text { DoR } \\
(\%)\end{array}$ & $\begin{array}{l}\text { FR } \\
(\%)\end{array}$ & $\begin{array}{l}\text { VI } \\
(\%)\end{array}$ \\
\hline \multicolumn{12}{|l|}{ RUTACEAE } \\
\hline Zanthoxylum rhoifolium Lam. & 10 & 1,2 & 0,4 & 2,0 & 3,7 & $\mathrm{Zc}$ & EI & 0,5 & 0,1 & 0,9 & 0,5 \\
\hline \multicolumn{12}{|l|}{ SALICACEAE } \\
\hline Casearia decandra Jacq. & 11 & 0,6 & 0,3 & 1,7 & 2,6 & $\mathrm{Zc}$ & EI & 0,8 & 0,4 & 1,6 & 0,9 \\
\hline Casearia obliqua Spreng. & 4 & 0,0 & 0,1 & 0,4 & 0,5 & $\mathrm{Zc}$ & EI & 4,4 & 1,8 & 3,9 & 3,4 \\
\hline Xylosma tweediana (Clos) Eichler & 5 & 0,0 & 0,3 & 0,5 & 0,8 & $\mathrm{Zc}$ & EI & - & - & - & - \\
\hline \multicolumn{12}{|l|}{ SAPINDACEAE } \\
\hline $\begin{array}{l}\text { Allophylus edulis (A. St.-Hil., Cambess. \& A. Juss.) } \\
\text { Radlk. }\end{array}$ & 33 & 3,0 & 4,2 & 2,2 & 9,5 & $\mathrm{Zc}$ & EI & 1,1 & 0,7 & 1,6 & 1,1 \\
\hline Cupania vernalis Cambess. & 16 & 2,8 & 1,4 & 1,3 & 5,5 & $\mathrm{Zc}$ & EI & 0,6 & 0,5 & 1,1 & 0,7 \\
\hline Matayba elaeagnoides Radlk. & 21 & 3,4 & 1,9 & 1,6 & 6,9 & $\mathrm{Zc}$ & EI & 5,0 & 10,0 & 4,1 & 6,4 \\
\hline \multicolumn{12}{|l|}{ SAPOTACEAE } \\
\hline Pouteria beaurepairei (Glaz. \& Raunk.) Baehni & 2 & 0,0 & 0,1 & 0,3 & 0,4 & $\mathrm{Zc}$ & ET & - & - & - & - \\
\hline \multicolumn{12}{|l|}{ SYMPLOCACEAE } \\
\hline Symplocos tenuifolia Brand & 2 & 0,0 & 0,0 & 0,3 & 0,3 & $\mathrm{Zc}$ & EI & 1,6 & 0,7 & 1,6 & 1,3 \\
\hline Symplocos tetrandra Mart. & 1 & 0,0 & 0,1 & 0,0 & 0,1 & $\mathrm{Zc}$ & ET & 0,0 & 0,0 & 0,1 & 0,1 \\
\hline \multicolumn{12}{|l|}{ THEACEAE } \\
\hline Laplacea fruticosa (Schrad.) Kobuski & 1 & 0,0 & 0,1 & 0,0 & 0,1 & An & ET & 0,1 & 0,0 & 0,2 & 0,1 \\
\hline \multicolumn{12}{|l|}{ WINTERACEAE } \\
\hline Drimys brasiliensis Miers & 1 & 0,0 & 0,0 & 0,3 & 0,3 & $\mathrm{Zc}$ & ET & 1,0 & 1,1 & 1,7 & 1,2 \\
\hline TOTAL & 433 & 30,4 & 27,1 & 42,4 & 100,0 & & & 80,8 & 80,2 & 75,5 & 79,0 \\
\hline
\end{tabular}

Onde: $\mathrm{RNC1}=$ todos os indivíduos lenhosos em regeneração com $20 \mathrm{~cm} \leq$ altura $(\mathrm{H}) \leq 50 \mathrm{~cm}$ e diâmetro à altura do colo $(\mathrm{DAC})<5 \mathrm{~cm} ; \mathrm{RNC2}=$ Todos os indivíduos lenhosos com $51 \mathrm{~cm} \leq \mathrm{H} \leq 1,30 \mathrm{~m}$ e DAC $<5 \mathrm{~cm}$; RNC3 = todos os indivíduos lenhosos com $\mathrm{H}>1,3 \mathrm{~m}$, e diâmetro a 1,30 m do solo (DAP) $<5 \mathrm{~cm}$. Ni: número de indivíduos da espécie amostrados dentro das três classes de tamanho; RNC: regeneração natural da i-ésima espécie na j-ésima classe de tamanho $(1,2,3) ; \mathrm{RNT}$ = regeneração natural total da i-ésima espécie; SD: síndrome de dispersão de diásporos; Zo: zoocórica; An: anemocórica; Au: autocórica; CS: classificação sucessional; EI: estágios iniciais; ET: estágios tardios; DR(\%): densidade relativa; DoR (\%): dominância relativa; FR(\%): frequência relativa; VI (\%): valor de importância. -: espécie ausente no estrato adulto.

Com relação à amostragem da regeneração, a curva de rarefação exibiu um intervalo de confiança para sete espécies dentro da suficiência amostral e o estimador de riqueza Bootstrap apontou que $87 \%$ das espécies estatisticamente possíveis de ocorrer foram amostradas (Figura 2).

O grau de similaridade florística entre a (RNT) e o estrato adulto e entre as classes de tamanho (RNC) estão apresentadas na Tabela 3. Valores acima de 50\% são considerados de alta similaridade florística, sendo observada uma progressão positiva entre o aumento das classes de altura em relação à similaridade com o estrato adulto.

As espécies que apresentaram os maiores valores de (RNT) foram Allophylus edulis (9,5\%), Mollinedia clavigera (8,5\%) e Myrciaria tenella (8,3\%), seguidas de Matayba elaeagnoides (6,9\%), Myrsine umbellata (5,7\%), Cupania vernalis (5,5\%), Cordia ecalyculata (4,5\%), Prunus myrtifolia (4,2\%), Campomanesia xanthocarpa (4,2\%) e Cinnamomum sellowianum $(3,9 \%)$ (Tabela 2$)$, tendo sua importância variando entre as classes de tamanho (RNC), como pode ser observado na Figura 3. 
Os parâmetros fitossociológicos da estrutura horizontal mostram que as espécies do estrato adulto compartilhadas com a regeneração representam $80,8 \%$ da densidade relativa (DR\%) da floresta estudada, assim como $80,2 \%$ da dominância relativa (DoR\%), 75,5\% da frequência relativa (\%) e $79 \%$ das espécies mais importantes (VI\%) (Tabela 2).

As espécies mais importantes do estrato adulto são Ocotea porosa (9,3\%), Araucaria angustifolia (6,5\%), Matayba elaeagnoides (6,4\%), Vernonanthura discolor
$(6,4 \%)$, Clethra scabra $(5,8 \%)$, Ilex paraguariensis (5,4\%), Myrsine umbellata (4,9\%) e Prunus myrtifolia $(4,6 \%)$, todas presentes também na regeneração.

A zoocoria foi a estratégia de dispersão de sementes predominante em todas as classes de regeneração e no estrato adulto, seguida de anemocoria e autocoria. Também predominaram as espécies do estágio inicial (EI) em relação as do estágio tardio (ET). Porém, a proporção de espécies de ET na RNC3 e RNT foi maior do que no estrato adulto e classes menores de regeneração (Figura 4).

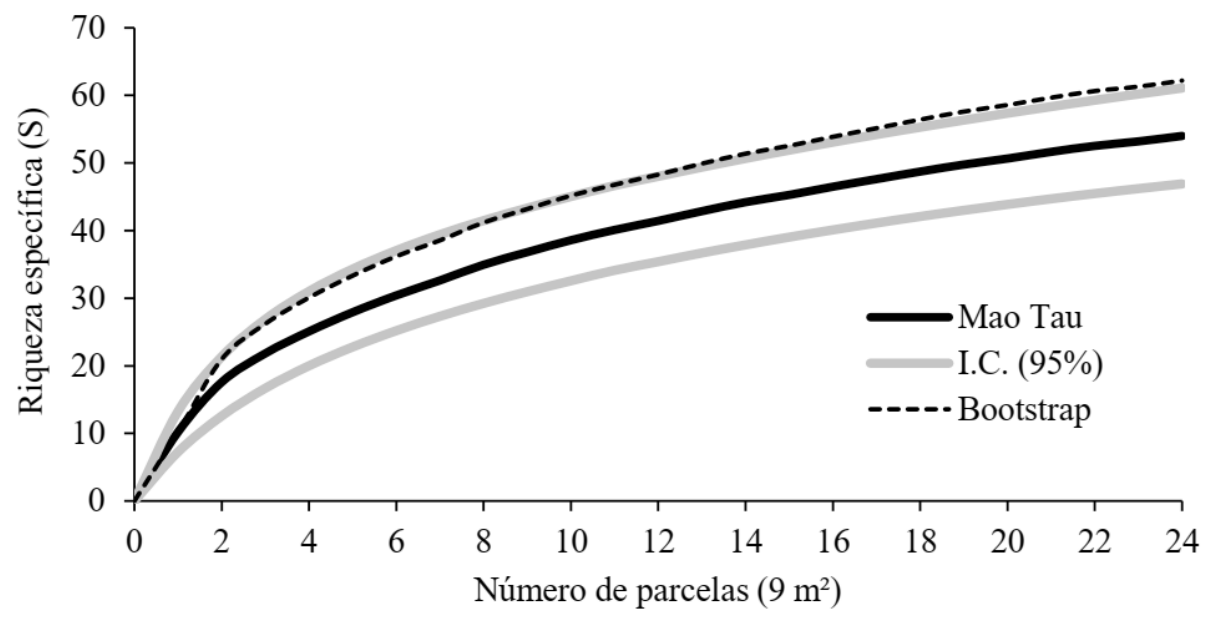

Figura 2. Curva de rarefação pelo método de Mao Tau com o intervalo de confiança a $95 \%$ e o estimador de riqueza específica Bootstrap para 24 parcelas circulares para a suficiência amostral da regeneração natural de uma Floresta Ombrófila Mista secundária em Turvo, PR.

Figure 2. Rarefaction curve by Mao Tau method with $95 \%$ confidence interval and the Bootstrap specific richness estimator for 24 circular plots for the sampling adequacy of the natural regeneration of a secondary Araucaria Forest in Turvo, Paraná State, Brazil.

Tabela 3. Similaridade florística entre o estrato adulto, da regeneração natural total (RNT) e entre as classes de tamanho da regeneração natural ( $\mathrm{RNC}$ 1, 2 e 3) de espécies arbustivo-arbóreas em um fragmento de Floresta Ombrófila Mista secundária em Turvo, PR.

Table 3. Floristic similarity between the adult strata of total natural regeneration (RNT) and between the natural regeneration size classes (RNC 1, 2 and 3) of woody species in a fragment of Araucaria Forest in Turvo, Paraná State, Brazil.

\begin{tabular}{ccccc}
\hline Classe de Altura & Estrato adulto & RNT & RNC3 & RNC2 \\
\hline RNT & $68,3 \%$ & & & \\
RNC3 & $60,7 \%$ & $92,0 \%$ & $66,7 \%$ & \\
RNC2 & $53,5 \%$ & $78,6 \%$ & $51,5 \%$ & $69,1 \%$ \\
RNC1 & $41,9 \%$ & $51,3 \%$ & & \\
\hline
\end{tabular}

Onde: $\mathrm{RNC} 1=$ todos os indivíduos lenhosos em regeneração com $20 \mathrm{~cm} \leq$ altura $(\mathrm{H}) \leq 50 \mathrm{~cm}$ e diâmetro à altura do colo $(\mathrm{DAC})<5 \mathrm{~cm} ; \mathrm{RNC} 2=$ Todos os indivíduos lenhosos com $51 \mathrm{~cm} \leq \mathrm{H} \leq 1,30 \mathrm{~m}$ e DAC $<5 \mathrm{~cm} ; \mathrm{RNC} 3$ = todos os indivíduos lenhosos com $\mathrm{H}>1,3 \mathrm{~m}$, e diâmetro a 1,30 m do solo (DAP) $<5 \mathrm{~cm}$. 


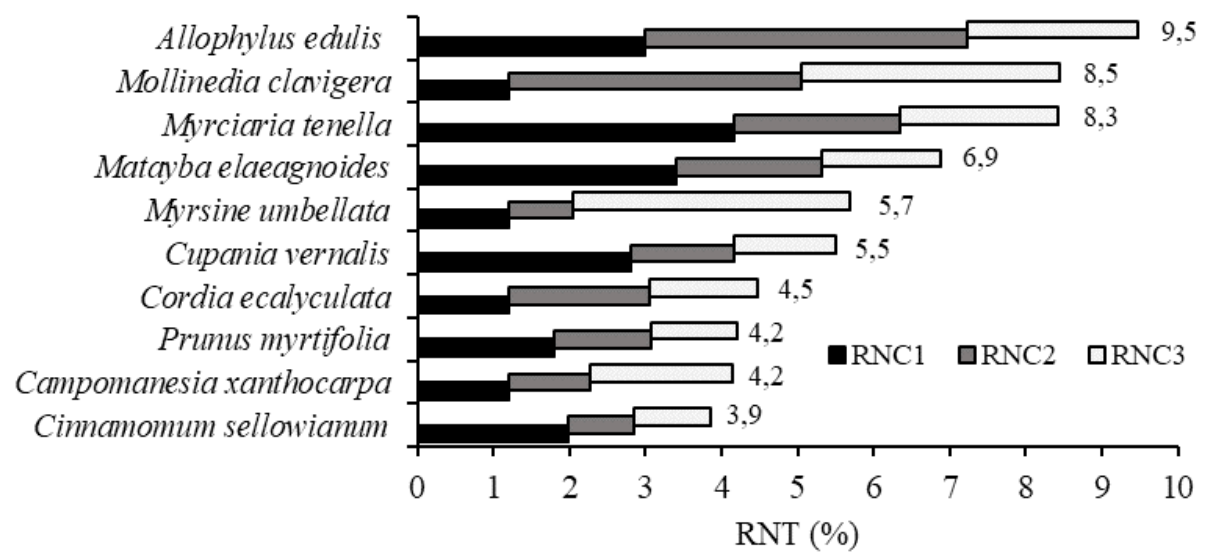

Figura 3. Espécies com maior valor de regeneração natural total (RNT) bem como sua representatividade em cada classe de altura analisada (RNC) em um fragmento de Floresta Ombrófila Mista Secundária em Turvo, PR. RNC1 = todos os indivíduos lenhosos em regeneração com $20 \mathrm{~cm} \leq$ altura $(\mathrm{H}) \leq 50 \mathrm{~cm}$ e diâmetro à altura do colo $(\mathrm{DAC})<5 \mathrm{~cm}$; RNC2 $=$ Todos os indivíduos lenhosos com $51 \mathrm{~cm} \leq \mathrm{H} \leq 1,30 \mathrm{~m}$ e DAC $<5 \mathrm{~cm}$; RNC3 = todos os indivíduos lenhosos com $\mathrm{H}>1,3 \mathrm{~m}$, e diâmetro a $1,30 \mathrm{~m}$ do solo $(\mathrm{DAP})<5 \mathrm{~cm}$.

Figure 3. Species with the highest total natural regeneration (RNT) value as well as their representativeness in eact size class analyzed (RNC) in y secondary Araucaria Forest fragment in Turvo, Paraná State, Brazil. RNC1 = all woody individuals in regeneration with $20 \mathrm{~cm} \leq$ height $(\mathrm{H}) \leq 50 \mathrm{~cm}$ and diameter at neck height $(\mathrm{DNH})<5 \mathrm{~cm}$; RNC2 = All woody individuals with $51 \mathrm{~cm} \leq \mathrm{H} \leq 1.30 \mathrm{~m}$ and $\mathrm{DNH}<5 \mathrm{~cm} ; \mathrm{RNC} 3=$ all woody individuals with $\mathrm{H}>1,3 \mathrm{~m}$ and diameter at 1,30 $\mathrm{m}$ from the soil $(\mathrm{DBH})<5 \mathrm{~cm}$.

a) Dispersão de sementes
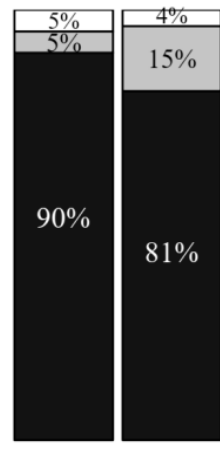

RNC 1
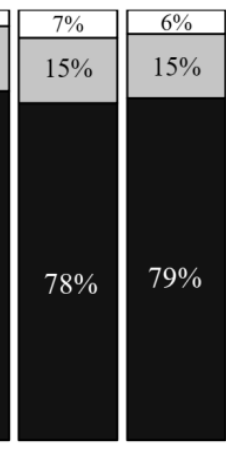

RNT

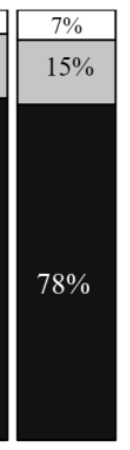

$\mathrm{ADU}$

घZoocoria $\square$ Anemocoria $\square$ Autocoria

b) Classificação ecológica

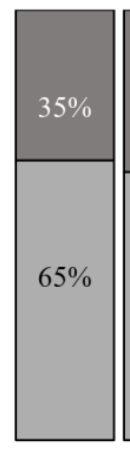

RNC 1 RNC 2

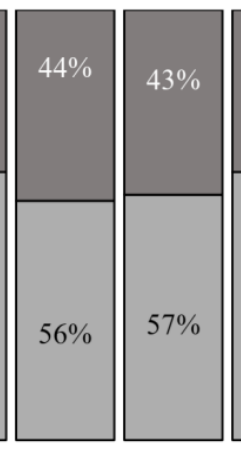

RNT

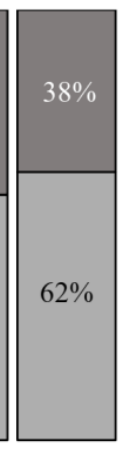

ADU
口Estágio Inicial $\square$ Estágio Tardio

Figura 4. a) Proporção de espécies por estratégia de dispersão de sementes e; b) classificação ecológica das espécies da regeneração natural total (RNT), por classe de tamanho (RNC 1,2,3) e estrato adulto (ADU) em um fragmento de Floresta Ombrófila Mista secundária em Turvo, PR. RNC1 = todos os indivíduos lenhosos em regeneração com $20 \mathrm{~cm} \leq$ altura $(\mathrm{H}) \leq$ $50 \mathrm{~cm}$ e diâmetro à altura do colo $(\mathrm{DAC})<5 \mathrm{~cm} ; \mathrm{RNC} 2=$ Todos os indivíduos lenhosos com $51 \mathrm{~cm} \leq \mathrm{H} \leq 1,30 \mathrm{~m}$ e DAC $<$ $5 \mathrm{~cm}$; RNC3 $=$ todos os indivíduos lenhosos com $\mathrm{H}>1,3 \mathrm{~m}$, e diâmetro a $1,30 \mathrm{~m}$ do solo (DAP) $<5 \mathrm{c}$

Figure 4. a) Proportion of species by seed dispersion strategy and; b) ecological classification of the species in the total natural regeneration (RNT), by size class (RNC 1, 2, 3) and adult stratum (ADU) in a secondary Araucaria Forest fragment in Turvo, Paraná Stat, Brazil.; RNC1 = all woody individuals in regeneration with $20 \mathrm{~cm} \leq$ height $(\mathrm{H}) \leq 50 \mathrm{~cm}$ and diameter at neck height $(\mathrm{DNH})<5 \mathrm{~cm} ; \mathrm{RNC} 2=$ All woody individuals with $51 \mathrm{~cm} \leq \mathrm{H} \leq 1.30 \mathrm{~m}$ and $\mathrm{DNH}<5 \mathrm{~cm} ; \mathrm{RNC} 3=$ all woody individuals with $\mathrm{H}>1,3 \mathrm{~m}$ and diameter at $1,30 \mathrm{~m}$ from the soil $(\mathrm{DBH})<5 \mathrm{~cm}$. 


\section{Discussão}

A curva de rarefação apresentou tendência à estabilização e o intervalo de confiança sugeriu que a amostragem foi satisfatória, mesmo sem atingir a assíntota. Além disto, observou-se que com a adição da última parcela houve um acréscimo médio de apenas $0,79 \%$ no número de novas espécies. A suficiência amostral ainda pode ser sustentada observando-se o estimador de riqueza Bootstrap, o qual apontou que $87 \%$ da riqueza específica estatisticamente esperada foi amostrada. Segundo Mallmann \& Schmitt (2014), porém, as estimativas analíticas de riqueza geradas não fornecem previsões precisas do número real de espécies em uma comunidade, mas apontam os valores mínimos esperados.

O gradiente de variações ambientais e bióticas intrínsecas de um ecossistema florestal, tais como clareiras, regiões mais úmidas, declivosas ou até mesmo o raio de dispersão de sementes das plantas matrizes, nem sempre são abrangidas pela amostragem. Portanto, mesmo com a utilização sistemática de amostragem neste estudo, algumas espécies ou guildas locais muito particulares podem não ter sido cobertas em razão do número de parcelas utilizadas.

Segundo Sccoti et al. (2011), a maior densidade de indivíduos nas classes de menor tamanho é comum em estudos de regeneração natural e um padrão em florestas inequiâneas, pois são na maioria das vezes resultado da grande produção de propágulos e plantas recém-estabelecidas. Porém, como também é esperado em florestas naturais, uma proporção consideravelmente menor consegue atingir as classes de maior de tamanho. Neste estudo observou-se diminuição na ordem de $30 \%$ a $35 \%$ na densidade de indivíduos a cada aumento de classe.

A similaridade entre a regeneração natural total (RNT) e o estrato adulto é alta e crescente com o aumento das classes de tamanho, indicando que parte das espécies das classes menores permanecem retidas em um gargalo demográfico, em especial a regeneração natural na classe 1 (RNC1), com indivíduos de 20 a $50 \mathrm{~cm}$ de altura. O fator de guinada da maior homogeneidade de similaridade parece se dar quando as plantas atingem a RNC2, com mais de $51 \mathrm{~cm}$ de altura, onde a similaridade com a RNT e o estrato adulto aumentam substancialmente.
Segundo Clark et al. (1999), filtros ambientais são resultados da baixa oferta de sementes em relação à demanda pela predação, a exposição de sementes e plantas à herbivoria, ao ataque de patógenos, sombreamento, luminosidade e ao estresse hídrico, onde o aumento da mortalidade em um determinado estágio ou o desacoplamento acentuado entre as probabilidades de recrutamento de etapas sucessivas podem levar a gargalos demográficos na regeneração, como vistos na transição da RNC1 para as demais classes.

A heterogeneidade ambiental a existência de microhabitats específicos e a oferta ineficiente de sementes podem afetar o sucesso da regeneração de algumas espécies (Rother et al., 2013). Isto indicaria até que ponto um local se apresenta como adequado e "seguro" ou um gargalo ao estabelecimento daquela espécie em relação à heterogeneidade de habitats a que são expostas e de como isso varia de acordo com as espécies e suas histórias de vida. Isto de fato parece influenciar o insucesso de ingresso de parte dos indivíduos da estrutura da floresta adulta, pois, apesar da diversidade e da equitatividade entre as classes serem crescentes, á dominância se mantém baixa conforme se aumenta a classe de tamanho.

Com relação à análise florística, a maior representatividade de Myrtaceae, Lauraceae, Sapindaceae, Euphorbiaceae e Salicaceae, tanto na regeneração como no estrato adulto, corrobora a afirmação de Santos et al. (2018), que relatam que estas famílias apresentam destaque em praticamente todos os estádios ontogênicos em estudos de Floresta Ombrófila Mista no Sul do Brasil, diferindo-se em poucos casos estágios mais incipientes de sucessão secundária com presença mais marcante de Asteraceae, com Fabaceae em zonas ecotonais de FOM ou mesmo fragmentos de Floresta com Araucária do Sudeste, onde a família Rubiaceae apresenta grande distinção no sub-bosque.

A riqueza da regeneração natural com 54 espécies está dentro dos padrões esperados, como indicado por Maçaneiro et al. (2016), que levantaram uma variação entre 39 e 109 espécies em estudos de regeneração natural em Floresta Ombrófila Mista, denotando o valor de importância do fragmento para conservação e estudos de florestas secundárias na FOM, em especial no Paraná. Ressalta-se, porém, que além dos sistemas de uso e perturbações inerentes de cada fragmento, esta amplitude de riqueza de espécies certamente é influenciada pelas diferentes metodologias de amostragem utilizadas. 
É notória a semelhança nos índices de diversidade (H'), equitatividade (J') e dominância (D) entre a RNC3, RNT e o estralto adulto, refletida na similaridade florística e na própria estrutura fitossociológica desta floresta. Estudos de premissa semelhante a este realizados na FOM, como de Maçaneiro et al. (2016), Santos et al. (2018), Fiorentin et al. (2015) e Kanieski et al. (2012) observaram valores semelhantes em diversidade, equitatividade e dominância, sendo destacado nestes estudos que estes valores apresentam, neste estrato da vegetação, grande relevância biológica para a conservação.

Com relação à estrutura do estrato regenerante, a espécie de presença mais marcante foi Allophylus edulis, comumente citada em estudos de regeneração natural na FOM, com frequência bem distribuída em todas as classes de altura, especialmente nas duas primeiras, porém, pouco importante no estrato adulto $(\mathrm{VI}=1,1 \%)$, apresentando baixa frequência e densidade.

Esta espécie, de acordo com Carvalho (2016), apresenta distribuição comum e abundante na Mata Atlântica, ocorrendo principalmente no estrato intermediário da floresta e de costumeira abundância na regeneração devido à estratégia zoocórica de dispersão de seus frutos. No estudo de Maçaneiro et al. (2016), Allophylus edulis foi a espécie mais importante na estrutura da regeneração. Os autores que relataram a espécie como de elevado número de indivíduos de menores tamanhos encontrados nos estratos médio e inferior da floresta. Pode-se sugerir, portanto, que mesmo apresentando um elevado valor de RNT nas classes menores, devido ao caráter mais heliófilo esta espécie não deve compor com grande destaque a estrutura adulta da floresta no futuro, devendo ser uma das espécies que normalmente ficam retidas nos estádios ontogênicos menores na regeneração destas florestas. Mollinedia claverigera também tem grande destaque no estrato regenerativo $(8,5 \%)$, principalmente nas duas maiores classes de altura ( $\mathrm{RNC} 2$ e RNC3). Porém, não foi encontrada no estrato adulto da floresta. Esta é uma espécie arbustiva classificada como de estágio tardio, bastante comum no sub-bosque da FOM (Selusniaki \& Acra, 2010). Conforme Peixoto et al. (2001), espécies do gênero Mollinedia possuem grande adaptação a ambientes com luz difusa, sem exigências pronunciadas quanto às condições edáficas, o que favorece sua ampla distribuição e abundância no sub-bosque, justificando a não ocorrência deste táxon na vegetação considerada adulta, devido à guilda especifica que ocupa e de não ultrapassar grandes diâmetros.
Myrciaria tenella $(\mathrm{RNT}=8,3 \%)$ apresentou grande representatividade na $\mathrm{C} 1$. Esta espécie, classificada como de estágio tardio, é uma arvoreta amplamente encontrada no sub-bosque de uma Floresta Ombrófila Mista aluvial (Barddal et al., 2004). De acordo Rayol et al. (2011), a espécie foi considerada pelos autores como indicadora de estágios de sucessão intermediários para este tipo de formação, devido à facilidade de estabelecimento da espécie em uma floresta secundária. M. tenella é parcamente representada na vegetação adulta (VI = $0,2 \%$ ), sugerindo-se que esta se mantém de fato no estrato de sub-bosque da floresta, não atingindo grandes diâmetros e alturas.

As duas espécies de Sapindaceae Matayba elaeagnoides $(\mathrm{RNT}=6,9 \%)$ e Cupania vernalis $(\mathrm{RNT}$ $=5,5 \%$ ) ocorreram em maior proporção na menor classe de tamanho (RNC1), sendo estas muito comuns em florestas secundárias em estágio inicial (capoeirões) e médio, encontrando-se também em grande abundância em FOM's secundárias em seu estádio adulto (Carvalho, 2006). Estas espécies, classificadas neste estudo como de estágio inicial (EI), ocorreram com grande importância em outros estudos de regeneração da FOM (Higuchi et al., 2015, Maçaneiro et al., 2016, Souza et al., 2018), porém, apresentam comportamento discrepante entre sua distribuição na regeneração e no estrato adulto.

C. vernalis apresenta bons parâmetros de regeneração, entretanto indica baixo valor de importância (VI = $0,7 \%$ ), enquanto que $M$. elaeagnoides tem grande representação na RNT e destacado valor de importância no estrato adulto $(\mathrm{VI}=6,4 \%)$. Ambas apresentam valores elevados na RNC1 e valores decrescentes nas classes seguintes, mas o indicativo é que $M$. elaeagnoides consegue melhor estabelecimento quando é recrutada para a estrutura adulta. Pscheidt et al. (2018) observaram grande plasticidade de ocorrência de $M$. elaeagnoides em ambientes de borda e ambientes sombreados, podendo ser esse um indicativo de que a espécie é mais generalista com maior indício de permanecer de maneira destacada na estrutura futura da floresta quando comparada com $C$. vernalis, que no mesmo estudo apontou ser mais seletiva, preferindo o interior da floresta e devendo ocorrer de maneira mais esporádica no estrato adulto.

As espécies Myrsine umbellata e Prunus myrtifolia exibem grande importância na RNC3 e são algumas das espécies mais importantes do estrato adulto (VI = $4,9 \%$ e $4,6 \%$, respectivamente), sugerindo uma grande capacidade de superar os crivos ambientais que possam 
ocorrer nos seus estágios ontogênicos mais incipientes e continuar na comunidade adulta futura da floresta estudada.

De acordo com Silva et al. (2007), as espécies que ocorrem em todas classes de altura de regeneração são, teoricamente, as que possuem maior potencial de estabelecimento na estrutura futura da floresta. Destas, Cinnamomum sellowianum e Coussarea contracta, classificadas como de estágio tardio, podem vir a ganhar importância com a progressão da sucessão. Inversamente, Vernonanthura discolor (VI = 6,4\%), espécie de (EI) muito importante no estrato adulto, apresenta pouca regeneração e deve ser substituída no futuro. De mesmo modo, algumas espécies EI que são fracamente representadas no estrato adulto, como Gymnanthes klotzschiana e Zanthoxylum rhoifolium, devem ocorrer de maneira menos frequente na floresta no futuro.

Das 54 espécies encontradas, 29 apresentaram menos de $1 \%$ do valor de RNT). Estas espécies apresentam menores chances de atingirem a fase adulta ou são espécies tardias que estão aguardando seu ingresso no ecossistema, tendendo a ser substituídas ao longo da sucessão florestal por outras mais destacadas na regeneração ou demandar mais tempo para tanto (Silva et al., 2007).

Ocotea porosa, que é uma das espécies-chave da FOM, foi a espécie mais importante (VI $=9,3 \%$ ) na comunidade arbórea adulta no fragmento estudado e apresenta indivíduos bem distribuídos nas três classes de tamanho de regeneração, indicando que esta tende a continuar ingressando na estrutura da floresta no futuro. Esta espécie é considerada a segunda mais importante da FOM, sendo longeva. Geralmente ocorre associada com Araucaria angustifoia, desempenhando um papel fundamental no desenvolvimento ecológico e, no passado, no desenvolvimento econômico e cultural nas regiões de abrangência da Floresta Ombrófila Mista (Caldato et al., 1999). Atualmente, a espécie é considerada em risco de extinção, reforçando a importância de conservação do fragmento estudado.

Outra espécte típica e frequente da Floresta com Araucária é Campomanesia xanthocarpa, espécie considerada de estágio tardio, porém que tolera sombra, especialmente nos solos úmidos da floresta aluvial, nos capões, e em áreas mais abertas da floresta secundária (Reitz, 1977). Essa espécie se destacou nas parcelas de regeneração no fragmento estudado $(\mathrm{RNT}=4,1 \%)$, com importância significativa no estrato adulto $(\mathrm{VI}=3,6 \%$ ), o que indica que apresenta boas chances de permanecer na floresta.

No entanto, a também longeva Ilex paraguariensis, outra espécie-chave na FOM devido à sua importância econômica, tem destaque no estrato adulto ( $\mathrm{VI}=5,4 \%)$, porém, com baixa RNT (1,2\%), indicando que terá dificuldade de apresentar novos ingressos no futuro e continuar na estrutura da floresta. Segundo Klein (1969), esta espécie tende a regenerar com maior facilidade quando o estrato arbóreo superior ou quando os estratos arbustivo e herbáceo são raleados.

Araucaria angustifolia apresentou regeneração muito baixa $(\mathrm{RNT}=0,5 \%)$, mesmo sendo a segunda espécie de maior importância do estrato adulto $(\mathrm{VI}=6,5 \%)$. Essa observação foi reportada em outros estudos (Higuchi et al., 2015). Devido a características intrínsecas da espécie, que é uma conífera de hábitos pioneiros, mas longeva, sua população permanece como dominante no dossel da floresta por longos períodos, mesmo produzindo escassa regeneração, garantindo a dinâmica da espécie no fragmento (Souza et al., 2008).

A. angustifolia apresenta uma fase crítica de desenvolvimento da regeneração, com alta mortalidade de plantas jovens (50 $\mathrm{cm}$ a $2 \mathrm{~m}$ de altura) em subbosques de florestas. Porém, a intensidade luminosa não parece ser um fator tão preponderante para o insucesso do estabelecimento da regeneração da espécie, que é bastante complexa e pode ser afetada por outras causas, como predação de sementes e plântulas recémgerminadas, sobreposição das mudas por serapilheira ou gramíneas, dentre outras, sendo necessários estudos mais aprofundados sobre a sua dinâmica sucessional (Paludo et al., 2009; Valente et al., 2010; Avila et al., 2013; Aguiar et al., 2017).

É notada a ausência no fragmento estudado de algumas espécies frequentes da FOM paranaense, como Casearia sylvestris Sw. (Salicaceae), Cinnamodendron dinisii Schwanke (Canellaceae), Ocotea puberula (Rich.) Nees (Lauraceae) e Sloanea hirsuta (Schott) Planch. ex Benth. (Elaeocarpaceae), encontradas apenas no estrato arbóreo com alta densidade de indivíduos (Mazon, 2014).

Esta lacuna deixada por estas espécies no estrato regenerativo pode ser resultado de falhas no estabelecimento das plântulas nas primeiras fases de regeneração, que segundo Silva et al. (2018), pode ser influenciada por diversos fatores, como existência 
e interações com dispersores primários e secundários ou predadores de sementes, forma e local em que os dispersores depositam suas sementes e também pela escala temporal necessária para o estabelecimento das plântulas destas espécies, que podem ser originárias da chuva de sementes pontual e do banco de sementes local, como também de outras áreas.

A maior proporção de espécies zoocóricas observada, tanto na regeneração como no estrato adulto, é muito mais notória em florestas neotropicais úmidas do que em áreas abertas e mais secas (Gentry, 1982). Segundo Tabarelli \& Peres (2002), em geral, espécies arbustivoarbóreas na Florestas Atlânticas que são dispersas por meios abióticos, são substituídas de maneira gradual pelas que são dispersas por vertebrados ao longo do processo de regeneração da floresta. Segundo estes autores, as espécies com frutos e sementes pequenos vão sendo substituídas por espécies de frutos e sementes de porte médio e grande por dispersores também maiores durante a sucessão secundária.

Isto se dá em consonância com o aumento do gradiente de complexidade da estrutura da comunidade vegetacional, que leva ao surgimento de novos habitats, recursos, relações biológicas e consequente maior oferta de nichos ecológicos, atraindo uma gama muito mais variada de dispersores que são inclusive cruciais para a conectividade funcional de paisagens (Howe, 2016). Essa característica pode ser usada como indicativo de que o presente fragmento está em pleno amadurecimento sucessional.

A proporção levemente maior de espécies do Estágio Inicial (EI) em relação às mais exigentes de sombra do grupo estágio tardio (ET) pode ser explicada de acordo com Seubert et al. (2017), porque as espécies exigentes em luz (EI) findaram em encontrar as condições adequadas para o seu estabelecimento a partir do isolamento da área, permitindo sua persistência até períodos posteriores, enquanto as condições ambientais são benéficas ao seu ingresso e estabelecimento.

A proporção de umbrófilas (ET) também é destacada, sendo estas espécies persistentes no banco de sementes e sua germinação é favorecida pela densidade de sombreamento do dossel (Silva Junior et al., 2004). No fragmento estudado observou-se a presença mais destacada de ET na RNC3 e RNT em relação ao estrato adulto, reforçando que a comunidade vegetal no local se encontra em estágio de amadurecimento sucessional.
Conforme Marimon et al. (2010), como a regeneração da vegetação florestal é um processo mútuo de interação entre as espécies e o meio físico, é esperado que com a mudança das condições ambientais o desenvolvimento dessas comunidades também se altere e, aliada ao aumento no sombreamento, ocorram contínuas alterações na composição florística e estrutura fitossociologia dessas florestas, em especial das espécies de ET da regeneração, como forma de adaptação a essas mudanças, denotando o caráter de desenvolvimento intermediário de sucessão desta floresta para o maduro, como é esperado.

\section{Conclusões}

A regeneração natural do fragmento estudado apresenta grande diversidade e alta similaridade com a vegetação do estrato adulto. As plantas que conseguem superar os filtros biológicos ou outro fator que não compõe o escopo deste estudo se estabelecem em sua grande maioria quando atingem a classe RNC2, acima dos $50 \mathrm{~cm}$ de altura.

Algumas das principais espécies da regeneração não apresentam relação com o estrato adulto, justificada em alguns casos por suas características autoecológicas, enquanto outras estão representadas tanto na regeneração como no estrato adulto.

Apesar da ligeira superioridade de plantas de estágio inicial em proporção às espécies de estágio tardio na regeneração, a proporção de espécies tardias é maior na classe de maior tamanho (RNC3) em relação às outras classes. A análise dessa observação em conjunto com a maior proporção de plantas zoocóricas sugere que o fragmento está em processo contínuo de rearranjo estrutural e amadurecimento sucessional.

Os resultados mostraram atributos florísticosestruturais e alguns atributos nos padrões de dinâmica e sucessão florestal, contribuindo para o entendimento de alguns padrões básicos de regeneração de algumas espécies típicas e de sucessão ecológica da Floresta Ombrófila Mista Paranaense, que podem ser profícuos em estudos futuros e tomadas de decisão visando à conservação florestal nesta fitofisionomia.

\section{Referências}

Avila, A. L. et al. Mecanismos de regeneração natural em remanescente de Floresta Ombrófila Mista, RS, Brasil. Cerne, v. 19, n. 4, p. 621-628, dez. 2013. http://dx.doi.org/10.5902/1980509824211. 
Aguiar, M. D. et al. Similaridade entre adultos e regenerantes do componente arbóreo em Floresta com Araucária. Floresta e Ambiente, v. 24, 2017. http://dx.doi.org/10.1590/2179-8087.083214.

Aide, T. M. et al. Forest regeneration in a chronosequence of tropical abandoned pastures: implications for restoration ecology. Restoration Ecology, v. 8, p. 328-338, 2000. http://dx.doi. org/10.1046/j.1526-100x.2000.80048.x.

Albuquerque, J. M. de. Regeneração natural de Floresta Ombrófila Mista em Sistema Faxinal no município de Rebouças-PR. Revista Eletrônica do Mestrado em Educação Ambiental, v. 33, n. 2, p. 20-33, 2016.

Alvares, C. A. et al. G. Köppen's climate classification map for Brazil. Meteorologische Zeitschrift, v. 22, n. 6, p. 711-728, 2013. http:// dx.doi.org/10.1127/0941-2948/2013/0507.

Barddal, M. L. et al. Fitossociologia do sub-bosque de uma Floresta Ombrófila Mista Aluvial, no município de Araucária, PR. Ciência Florestal, v. 14, n. 1, p. 35-45, 2004.

Caldato, S. L. et al. Estrutura populacional de Ocotea porosa (Lauraceae) em uma Floresta Ombrófila Mista, em Caçador (SC). Ciência Florestal, v. 9, n. 1, p. 89-101, 1999.

Carvalho, P. E. R. Espécies arbóreas brasileiras. Brasília, DF: Embrapa Informação Tecnológica; Colombo: Embrapa Florestas, 2006.

Chase, M. W. et al. An update of the Angiosperm Phylogeny Group classification for the orders and families of flowering plants: APG IV. Botanical Journal of the Linnean Society, v. 181, n. 1, p. 1-20, 2016. https://doi.org/10.1111/boj.12385.

Chazdon, R. L. Regeneração de florestas tropicais. Boletim do Museu Paraense Emílio Goeldi: Ciências Naturais, v. 7, n. 3, p. 195-218, 2012.

Clark, J. S. et al. Interpreting recruitment limitation in forests. American Journal of Botany, v. 86, n. 1, p. 1-16, 1999.

Cordeiro, J. \& Rodrigues, W. A. Regeneração natural do componente arbóreo em área de Floresta Ombrófila Mista, Guarapuava, PR. Revista Brasileira de Biociências, v. 5, n. S2, p. 825-827, 2007.

Ebling, A. A. et al. Alterações florísticas e estruturais em Floresta com Araucária no estado do Rio Grande do Sul, Brasil. Agrarian Academy, v. 1, n. 1, p. 1-27, 2014. http://dx.doi.org/ 10.18677Agrarian_Academy_2014_002.

Ferreira, P. I. et al. Espécies potenciais para recuperação de áreas de preservação permanente no Planalto Catarinense. Floresta e Ambiente, v. 20, n. 2, p. 173-182, 2013. http://dx.doi.org/10.4322/ floram.2013.003.

Fiorentin, L. D. et al. Análise florística e padrão espacial da regeneração natural em área de Floresta Ombrófila Mista na região de Caçador, SC. Floresta e Ambiente, v. 22, n. 1, p. 60-70, 2015. http://dx.doi.org/10.1590/2179-8087.071413.

Freitas, W. K. \& Magalhães, L. M. S. Métodos e parâmetros para estudo da vegetação com ênfase no estrato arbóreo. Floresta e Ambiente, v. 19, n. 4, p. 520-539, 2012. http://dx.doi.org/10.4322/ floram.2012.054.
Gentry, A. H. Neotropical floristic diversity: phytogeographical connections between Central and South America, pleistocene climatic fluctuations, or an accident of the andean orogeny? Annals of the Missouri Botanical Garden, v. 69, n. 3, p. 557-593, 1982. http:// dx.doi.org/10.2307/2399084.

Gotelli, N. J. \& Colwell, R. K. Estimating species richness. In: Magurran, A. E. \& McGill, B. J. Biological diversity: frontiers in measurement and assessment. Oxford: Oxford University, 2011. p. $39-54$.

Grings, M. \& Brack, P. Árvores na vegetação nativa de Nova Petrópolis, Rio Grande do Sul. Iheringia. Série Botânica, v. 64, p. 5-22, 2009.

Higuchi, P. et al. Fatores determinantes da regeneração natural em um fragmento de Floresta com Araucária no planalto catarinense. Scientia Forestalis, v. 43, n. 106, p. 10, 2015.

Howe, H. F. Making dispersal syndromes and networks useful in tropical conservation and restoration. Global Ecology and Conservation, v. 6, p. 152-178, 2016. http://dx.doi.org/10.1016/j. gecco.2016.03.002.

Kanieski, M. R. et al. Diversidade e padrões de distribuição espacial de espécies no estágio de regeneração natural em São Francisco de Paula, RS, Brasil. Floresta, v. 42, n. 3, p. 509-518, 2012. http:// dx.doi.org/10.5380/rf.v42i3.25037.

Klauberg, C. et al. Florística e estrutura de um fragmento de Floresta Ombrófila Mista no Planalto Catarinense. Biotemas, v. 23, n. 1, p. 35-47, 2010. http://dx.doi.org/10.5007/2175-7925.2010v23n1p35.

Klein, R. M. Árvores nativas da Ilha de Santa Catarina. Insula, n. 3, p. 3-93, 1969.

Lima, R. et al. Composição florística da regeneração natural em Floresta Ombrófila Mista. Revista Acadêmica Ciência Animal, v. 11, p. 113-120, 2013. http://dx.doi.org/10.7213/academica.10. S01.AO13.

Lugo, A. E. The emerging era of novel tropical forests. Biotropica, v. 41, n. 5, p. 589-591, 2009. http://dx.doi.org/10.1111/j.17447429.2009.00550.x.

Maçaneiro, J. P. de. et al. Regeneração de uma Floresta Ombrófila Mista no Planalto Catarinense. Biotemas, v. 29, n. 4, p. 31-42, 2016. http://dx.doi.org/10.5007/2175-7925.2016v29n4p31.

Mallmann, I. T. \& Schmitt, J. L. Riqueza e composição florística da comunidade de samambaias na mata ciliar do Rio Cadeia, Rio Grande do Sul, Brasil. Ciência Florestal, v. 24, n. 1, p. 97-109, 2014. http:// dx.doi.org/10.5902/1980509813327.

Marimon, B. S. et al. Environmental determinants for natural regeneration of gallery forest at the Cerrado/Amazonia boundaries in Brazil. Acta Amazonica, v. 40, n. 1, p. 107-118, 2010. http:// dx.doi.org/10.1590/S0044-59672010000100014.

Martins, L. \& Cavararo, R. Manual técnico da vegetação brasileira: sistema fitogeográfico, inventário das formações florestais e campestres, técnicas e manejo de coleções botânicas, procedimentos para mapeamentos. 2. ed. Rio de Janeiro: IBGE, 2012. 
Mazon, J. A. Composição florística e fitossociológica de Floresta Ombrófila Mista em áreas sob manejo silvipastoril e sucessão secundária. 2014. 158 f. Dissertação (Mestrado em Ciências Florestais) - Universidade Estadual do Centro-Oeste, Irati.

Medeiros, J. de D. et al. Seleção de áreas para criação de Unidades de Conservação na Floresta Ombrófila Mista. Biotemas, v. 18, n. 2 , p. 33-50, 2005. http://dx.doi.org/10.5007/\%25x.

Paludo, G. F. et al. Estrutura demográfica e padrão espacial de uma população natural de Araucaria angustifolia (Bertol.) Kuntze (Araucariaceae), na Reserva Genética Florestal de Caçador, Estado de Santa Catarina. Revista Árvore, v. 33, n. 6, p. 1109-1121, 2009. http://dx.doi.org/10.1590/S0100-67622011000600017.

Peixoto, A. L. et al. Monimiáceas. Itajaí: Herbário Barbosa Rodrigues, 2001. 64 p. (Flora Ilustrada Catarinense).

Piazza, G. E. et al. Regeneração natural de espécies madeireiras na floresta secundária da Mata Atlântica. Advances in Forestry Science, v. 4, n. 2, p. 99-105, 2017.

Pscheidt, F. et al. efeito de borda como fonte da heterogeneidade do componente arbóreo em uma floresta com araucária no sul do Brasil. Ciência Florestal, v. 28, n. 2, p. 601-612, 2018. http://dx.doi.org/ 10.5902/1980509832046

Rayol, B. P. et al. Similaridade florística entre o estrato arbóreo e a regeneração natural de uma floresta secundária, no município de Bragança, nordeste do estado do Pará, Brasil. Revista Brasileira de Agroecologia, v. 6, n. 3, p. 107-114, 2011.

Reitz, P. R. Mirtáceas. Itajaí, Herbário Barbosa Rodrigues, 1977. (Flora Ilustrada Catarinense).

Ribeiro, T. M. et al. Mixed rain forest in southeastern Brazil: tree species regeneration and floristic relationships in a remaining stretch of forest near the city of Itaberá, Brazil. Acta Botanica Brasilica, v. 27, n. 1, p. 71-86, 2013. http://dx.doi.org/10.1590/ S0102-33062013000100010.

Rother, D. C. et al. Demographic bottlenecks in tropical plant regeneration: A comparative analysis of causal influences. Perspectives in Plant Ecology, Evolution and Systematic, v.15, p. 86-96, 2013. http://dx.doi.org/10.1016/j.ppees.2012.12.004.

Santos, G. N. et al. Regeneração natural em uma Floresta com Araucária: inferências sobre o processo de construção da comunidade de espécies arbóreas. Ciência Florestal, v. 28, n. 2, p. 483-494, 2018. http://dx.doi.org/10.5902/1980509832029.

Santos, H. G. dos et al. Sistema brasileiro de classificação de solos. 3. ed. rev. e ampl. Brasília, DF: Embrapa, 2013. 353 p.

Sccoti, M. S. V. et al. Mecanismos de regeneração natural em remanescente de Floresta Estacional Decidual. Ciência Florestal, v. 21, n. 3, p. 459-472, 2011. http://dx.doi.org/10.5902/198050983803.

Selusniaki, M. \& Acra, L. A. O componente arbóreo-arbustivo de um remanescente de Floresta com Araucária no município de Curitiba, Paraná. Floresta, v. 40, n. 3, p. 593-602, 2010. http://dx.doi. org/10.5380/rf.v40i3.18921.
Seubert, R. C. et al. Regeneração natural em diferentes períodos de abandono de áreas após extração de Eucalyptus grandis Hill ex Maiden, em argissolo vermelho-amarelo álico, em Brusque, Santa Catarina. Ciência Florestal, v. 27, n. 1, p. 1-19, 2017. http://dx.doi. org/10.5902/1980509826443.

Silva, A. C. et al. Caracterização fitossociológica e fitogeográfica de um trecho de floresta ciliar em Alfredo Wagner, SC, como subsídio para restauração ecológica. Ciência Florestal, v. 23, n. 4, p. 579-593, 2013. http://dx.doi.org/10.5902/1980509812342.

Silva, J. P. G. et al. Chuva de sementes e estabelecimento de plântulas em floresta tropical na região nordeste do Brasil. Ciência Florestal, v. 28, n. 4, p. 1478-1490, 2018. http://dx.doi. org/10.5902/1980509835095.

Silva Júnior, W. M. da. et al. Regeneração natural de espécies arbustivo-arbóreas em dois trechos de uma Floresta Estacional Semidecidual, Viçosa, MG. Scientia Forestalis, v. 66, p. 169-179, 2004.

Silva, W. C. et al. Estudo da regeneração natural de espécies arbóreas em fragmento de Floresta Ombrófila Densa, Mata das Galinhas, no município de Catende, zona da mata sul de Pernambuco. Ciência Florestal, v. 17, n. 4, p. 321-331, 2007. http://dx.doi. org/10.5902/198050981964.

Souza, A. F. et al. Regeneration patterns of a long-lived dominant conifer and the effects of logging in southern South America. Acta Oecologica, v. 34, n. 2, p. 221-231, 2008. http://dx.doi.org/10.1016/j. actao.2008.05.013.

Souza, C. C. et al. Potencial regenerativo de uma floresta ecotonal na região do alto Uruguai em Santa Catarina. Ciência Florestal, v. 28, n. 1, p. 345-356, 2018. http://dx.doi.org/10.5902/1980509831605.

Tabarelli, M. \& Peres, C. A. Abiotic and vertebrate seed dispersal in the Brazilian Atlantic forest: implications for forest regeneration. Biological Conservation, v. 106, n. 2, p. 165-176, 2002. http:// dx.doi.org/10.1016/S0006-3207(01)00243-9.

Valente, T. P. et al. Regeneração de Araucaria angustifolia em três fitofisionomias de um fragmento de Floresta Ombrófila Mista. Iheringia. Série Botânica, v. 65, n. 1, p. 17-24, 2010.

Van Der Pijl, L. Principles of dispersal in higher plants. Berlin: Springer-Verlag, 1982. 214 p.

Volpato, M. M. L. Regeneração natural em uma floresta secundária no domínio de Mata Atlântica: uma análise fitossociológica. 1994. 123 f. Dissertação (Mestrado em Ciência Florestal) - Universidade Federal de Viçosa, Viçosa, MG.

Zama, M. Y et al. Florística e síndromes de dispersão de espécies arbustivo-arbóreas no Parque Estadual Mata São Francisco, PR, Brasil. Hoehnea, v. 39, n. 3, p. 369-378, 2012. http://dx.doi. org/10.1590/S2236-89062012000300002. 